\title{
Nature of Electromagnetic Emission Precursory to an Earthquake
}

\author{
Tsuneji RIKITAKE \\ Association for the Development of Earthquake Prediction, 1-5-18 Sarugaku-cho, Chiyoda-ku, Tokyo 101, Japan
}

(Received November 20, 1996; Revised June 30, 1997; Accepted July 1, 1997)

\begin{abstract}
More than 60 occurrences of electromagnetic emission data in Japan precursory to an earthquake are analyzed. It turns out that the larger the main shock magnitude $(M)$, the larger the detectable distance $\left(D_{\max }\right)$ of signal from the epicenter. The $M-D_{\max }$ relation agrees with that of other geophysical precursors. No dependence of precursor time $(T)$ on $M$ is observed. The situation is much the same as foreshock precursor. The mean precursor time of electromagnetic radiation precursor amounts to 0.26 day, so that the precursor is essentially a short-term one.
\end{abstract}

\section{Introduction}

Anomalous electromagnetic emissions precursory to an earthquake have recently been reported in Japan and foreign countries (e.g. Fraser-Smith et al., 1990; Yoshino et al., 1993; Oike and Murakami, 1993; Oike and Yamada, 1994; Fujinawa and Takahashi, 1994). The electromagnetic noises in LF and VLF bands received at Uji near Kyoto in association with the Kobe earthquake of magnitude $(M) 7.2$, that occurred on Jan. 17, 1995, are highly impressive (Faculty of Science, Kyoto University, 1995). There are also many reports on radio noises observed by amateurs and commercial radio receivers on that occasion.

Since it appears that many data of precursor-like electromagnetic emissions have been accumulated in Japan, this paper will analyze those data in the hope of clarifying the physical nature of such emissions mostly basing on the reports by Kyoto University, University of Electro-Communications and National Research Institute for Earth Science and Disaster Prevention.

\section{Observation}

The data analyzed in this paper have been taken by the following three groups: Faculty of Science, Kyoto University represented by Professor K. Oike, University of Electro-Communications represented by Professor T. Yoshino, and National Research Institute for Earth Science and Disaster Prevention represented by Dr. Y. Fujinawa.

The essentials of observation by the three groups are as follows.

\subsection{Faculty of Science, Kyoto University}

Oike and his group have been making observation of electromagnetic emissions in LF band at Uji Station close to Kyoto City as shown in Fig. 1 since 1983. Details of the observation system are seen elsewhere (Oike and Ogawa, 1986). Making use of a ball antenna, amplified signals are counted after filtering. The number of signals counted is converted into analogue voltage and recorded on a running chart. A fixed frequency band at $163 \mathrm{kHz}$ is used although observation of $1 \sim 10 \mathrm{kHz}$ band is added later.

It should be specially mentioned that remarkably intense emissions are observed at the station located at a point which is only $80 \mathrm{~km}$ distant from the epicenter of the Jan. 17, 1995, Kobe earthquake $(M=7.2)$. Essentials of the observation facilities are summarized in Table 1. 


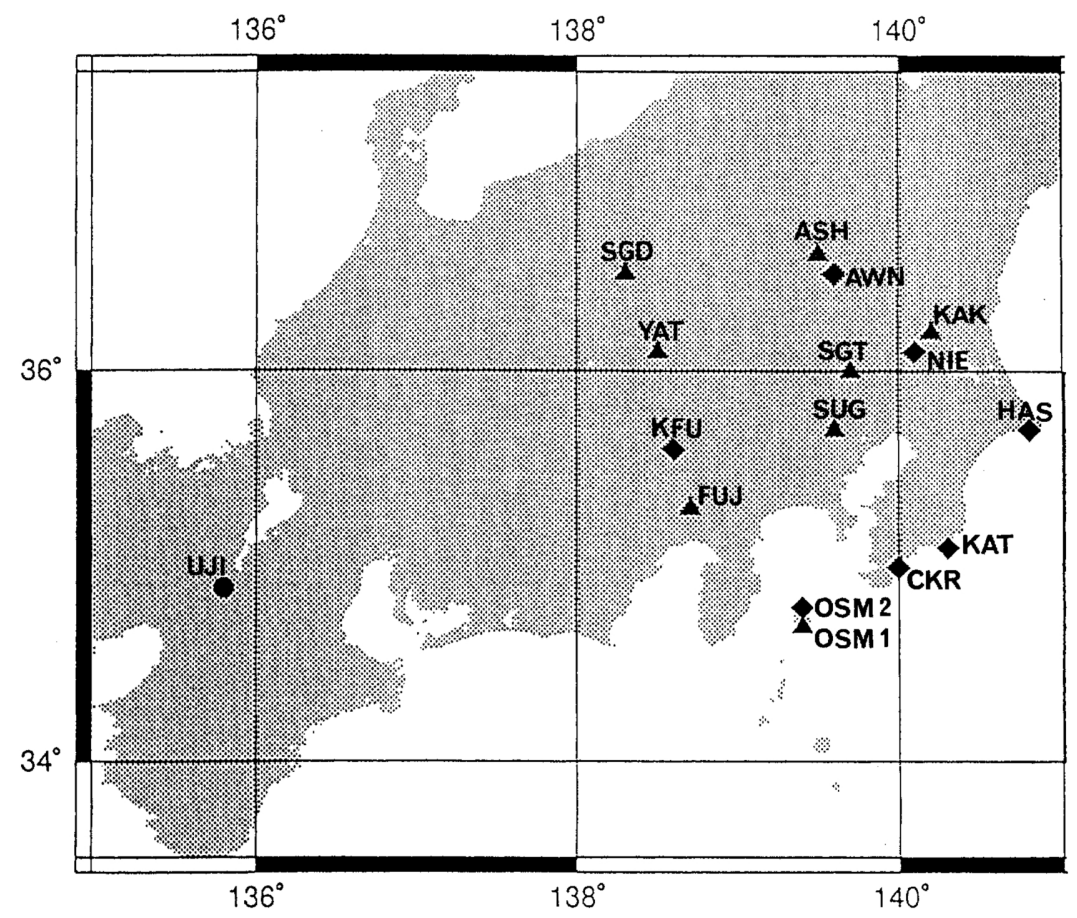

Fig. 1. Locations of observation points for electromagnetic emission. Stations denoted by $\boldsymbol{\bullet}, \boldsymbol{\Delta}$ and $\bullet$ are operated by Kyoto University, University of Electro-Communications and National Research Institute for Earth Science and Disaster Prevention, respectively. All the abbreviations are defined in Tables 2 and 3.

Table 1. Essentials of the observation by Kyoto University.

\begin{tabular}{ccc}
\hline Observation point & Frequency observed & Indication of anomalous emission \\
\hline Uji, Kyoto Pref. & LF $(163 \mathrm{kHz})$ & Number of impulsive noise \\
$\left(34.9^{\circ} \mathrm{N}, 135.8^{\circ} \mathrm{E}\right)$ & VLF $(1-10 \mathrm{kHz})$ & \\
\hline
\end{tabular}

\subsection{University of Electro-Communications}

Yoshino and his group have been working on monitoring anomalous electromagnetic emissions since 1980. A standard system for observation having two sets of magnetic sensor for $1.525 \mathrm{kHz}$ and $36 \mathrm{~Hz}$ observation and a set of two loop antennas for $82 \mathrm{kHz}$ observation has now been developed. Output signals, that pass through an A/D converter are telemetered to an observation center. Data are also recorded on digital tapes and hard disks at each station. No further details of the system are given here. Those who are particularly interested in more detail should refer to Yoshino et al. (1993).

As summarized in Table 2, observations are now conducted at eight stations in the Kanto-Shinetsu area around Tokyo. The locations of observation station are shown in Fig. 1.

\subsection{National Research Institute for Earth Science and Disaster Prevention}

As described by Fujinawa and Takahashi (1994), they have been measuring electric signals monitored by an underground antenna since around 1990. Although the merit of the observation system using such an antenna is not quite convincing, the Fujinawa group has been using a vertical steel pipe of several hundred meters in length buried in the ground for an element of antenna. Electric potential 
Table 2. Essentials of the observation by the University of Electro-Communications.

\begin{tabular}{|c|c|c|c|}
\hline Observation point & Abbreviation & Frequency used & Indication of anomalous emission \\
\hline $\begin{array}{l}\text { Ashio } \\
\left(36.6^{\circ} \mathrm{N}, 139.5^{\circ} \mathrm{E}\right)\end{array}$ & ASH & & \\
\hline $\begin{array}{l}\text { Sugadaira } \\
\left(36.5^{\circ} \mathrm{N}, 138.3^{\circ} \mathrm{E}\right)\end{array}$ & SGD & & \\
\hline $\begin{array}{l}\text { Kakioka } \\
\left(36.2^{\circ} \mathrm{N}, 140.2^{\circ} \mathrm{E}\right)\end{array}$ & KAK & & \\
\hline $\begin{array}{l}\text { Yatsugatake } \\
\left(36.1^{\circ} \mathrm{N}, 138.5^{\circ} \mathrm{E}\right)\end{array}$ & YAT & $\begin{array}{l}\text { LF }(82 \mathrm{kHz}) \\
\text { VLF }(1.525 \mathrm{kHz}) \\
\text { ELF }(36 \mathrm{~Hz})\end{array}$ & Change in background noise level \\
\hline $\begin{array}{l}\text { Sugito } \\
\left(36.0^{\circ} \mathrm{N}, 139.7^{\circ} \mathrm{E}\right)\end{array}$ & SGT & & \\
\hline $\begin{array}{l}\text { Suginami } \\
\left(35.7^{\circ} \mathrm{N}, 139.6^{\circ} \mathrm{E}\right)\end{array}$ & SUG & & \\
\hline $\begin{array}{l}\text { Fujinomiya } \\
\left(35.3^{\circ} \mathrm{N}, 138.7^{\circ} \mathrm{E}\right)\end{array}$ & FUJ & & \\
\hline $\begin{array}{l}\text { Oshima } \\
\left(34.7^{\circ} \mathrm{N}, 139.4^{\circ} \mathrm{E}\right)\end{array}$ & OSM 1 & & \\
\hline
\end{tabular}

Table 3. Essentials of the observation by National Research Institute for Earth Science and Disaster Prevention.

\begin{tabular}{|c|c|c|c|}
\hline Observation point & Abbreviation & Frequency used & Indication of anomalous emission \\
\hline $\begin{array}{l}\text { Awano } \\
\left(36.5^{\circ} \mathrm{N}, 139.6^{\circ} \mathrm{E}\right)\end{array}$ & AWN & & \\
\hline $\begin{array}{l}\text { Tsukuba } \\
\left(36.1^{\circ} \mathrm{N}, 140.1^{\circ} \mathrm{E}\right)\end{array}$ & NIE & & \\
\hline $\begin{array}{l}\text { Hasaki } \\
\qquad\left(35.7^{\circ} \mathrm{N}, 140.8^{\circ} \mathrm{E}\right)\end{array}$ & HAS & & \\
\hline $\begin{array}{l}\text { Kofu } \\
\left(35.6^{\circ} \mathrm{N}, 138.6^{\circ} \mathrm{E}\right)\end{array}$ & KFU & $\begin{array}{l}\text { d.c. }(0 \sim 0.7 \mathrm{~Hz}) \\
\text { ULF }(0.01 \sim 0.7 \mathrm{~Hz}) \\
\text { VLF }(9 \mathrm{kHz})\end{array}$ & Number of impulsive noise \\
\hline $\begin{array}{l}\text { Katsuura } \\
\left(35.1^{\circ} \mathrm{N}, 140.3^{\circ} \mathrm{E}\right)\end{array}$ & KAT & & \\
\hline $\begin{array}{l}\text { Chikura } \\
\left(35.0^{\circ} \mathrm{N}, 140.0^{\circ} \mathrm{E}\right)\end{array}$ & CKR & & \\
\hline $\begin{array}{l}\text { Oshima } \\
\left(34.8^{\circ} \mathrm{N}, 139.4^{\circ} \mathrm{E}\right)\end{array}$ & OSM 2 & & \\
\hline
\end{tabular}




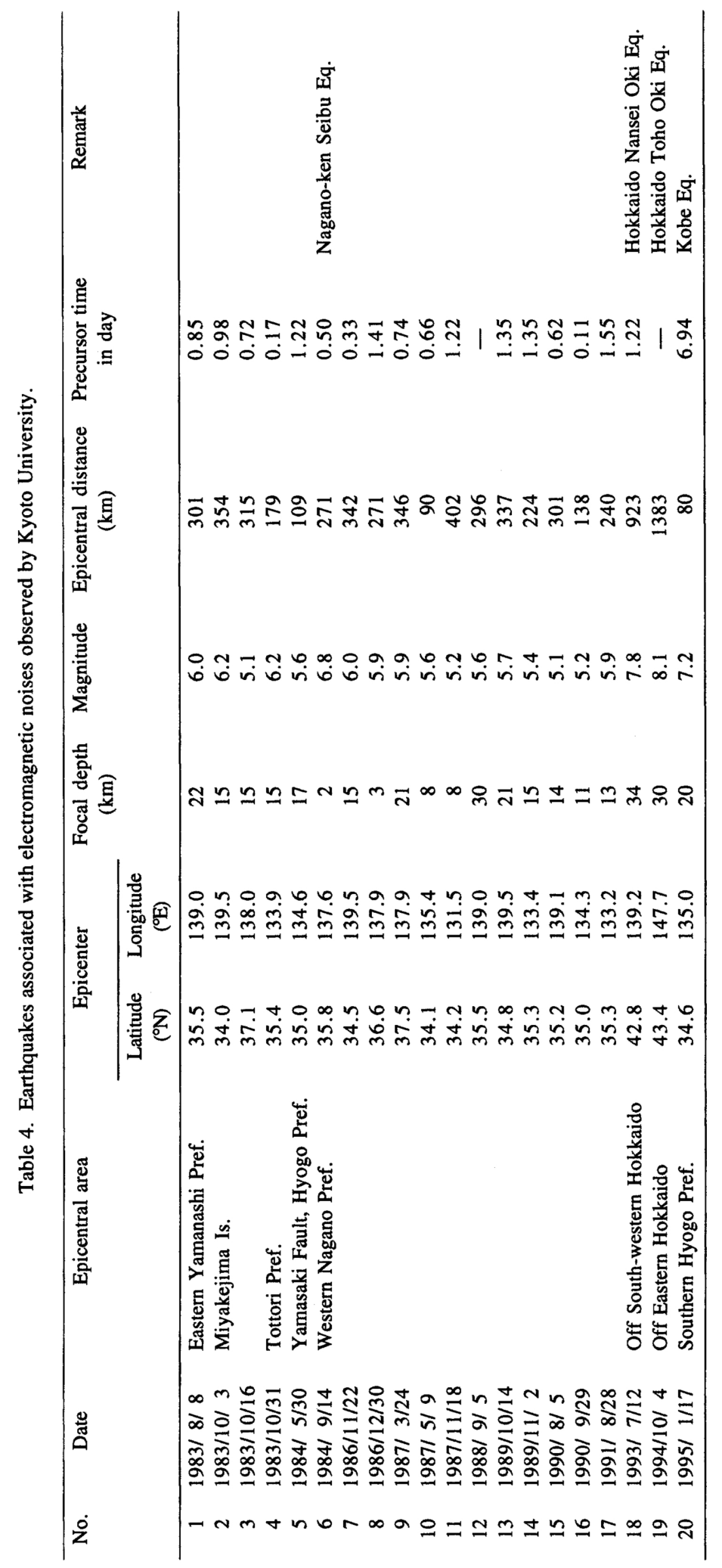




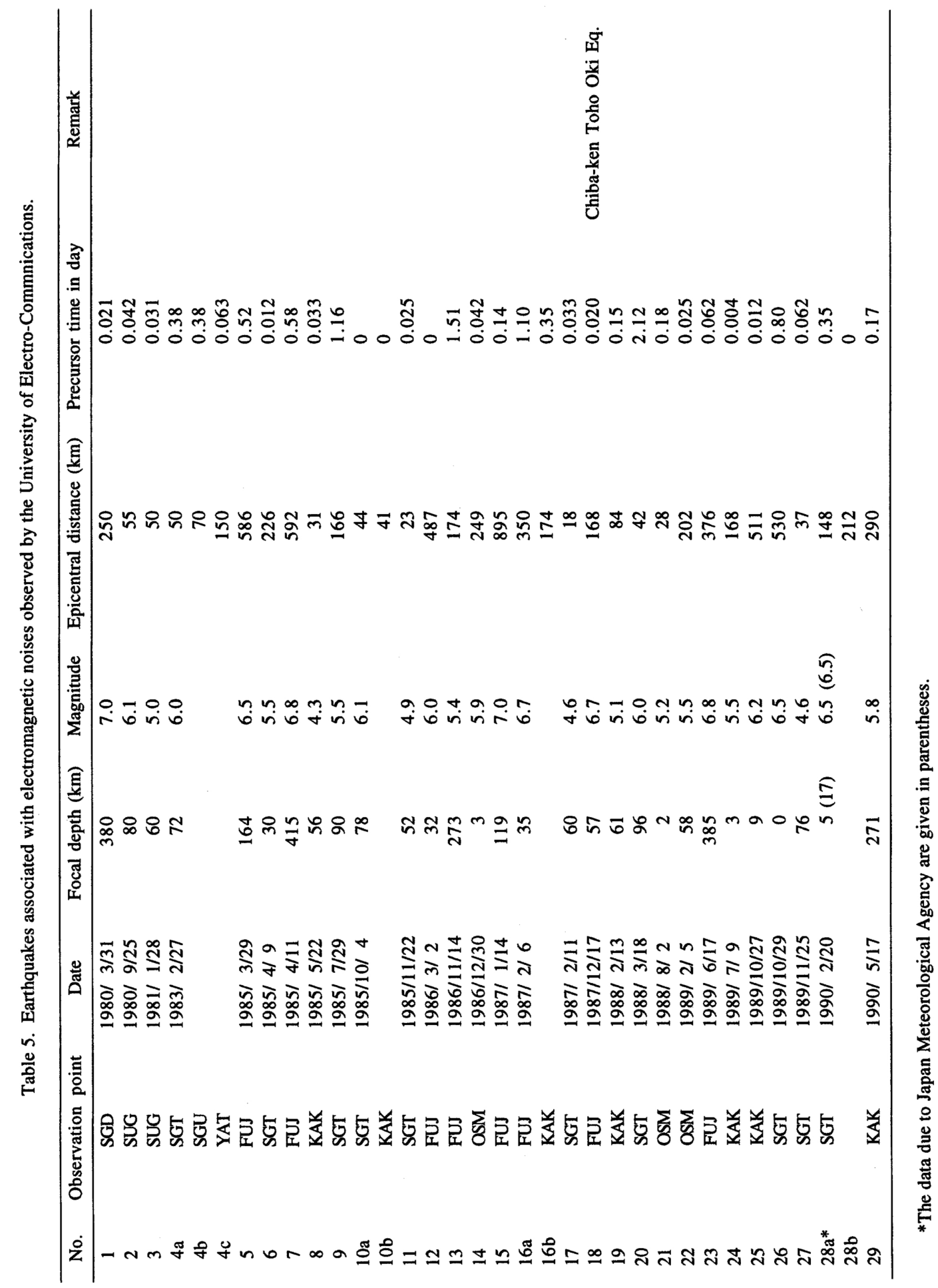




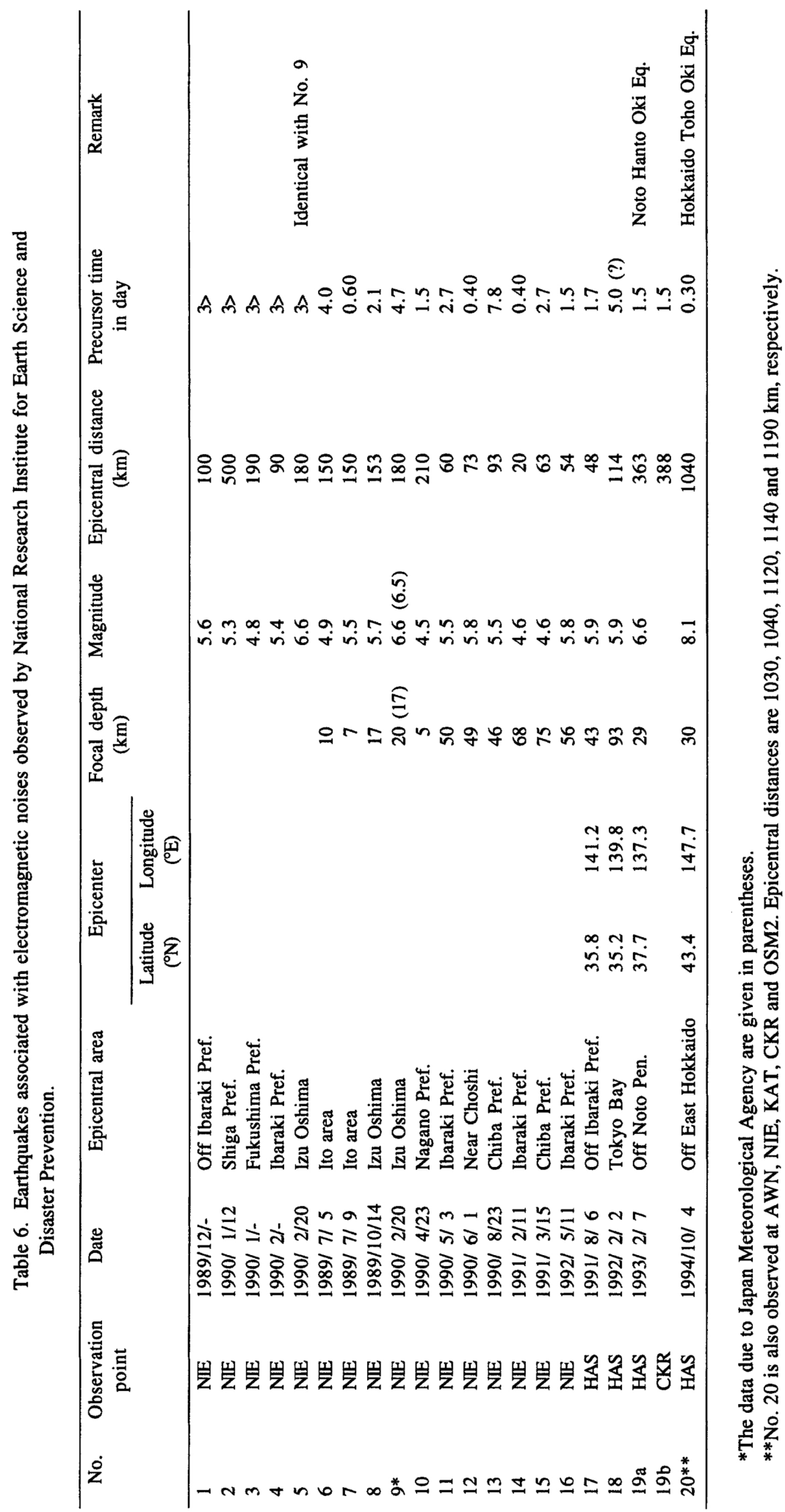


difference between such an antenna and a loop of 40 100 $\mathrm{m}$ in radius grounded at a depth of $1 \mathrm{~m}$ surrounding the antenna is recorded.

Observations are made at d.c., ULF and VLF bands as shown in Table 3 in which the locations of seven stations in the Kanto area are also given. The Tsukuba station abbreviated as NIE serves as the central base for the experiment to which most data are telemetered. The locations of these stations are shown in Fig. 1 along with those for other organizations.

\section{Precursor-like Data Obtained}

Precursor-like electromagnetic signals prior to an earthquake have been reported by the three groups in a variety of reports from time to time. These are summarized below.

\subsection{Data by Kyoto University}

The results of Kyoto University group's observations are summarized in Table 4. The data from No. 1 to No. 17 are taken from Oike and Murakami (1993) and Nos. 18 and 19 from Oike and Yamada (1994), while No. 20 from Faculty of Science, Kyoto University (1995).

The original data do not always indicate epicentral distances between Uji, where the observation is performed, and the epicenter, so distances are calculated from the latitudes and longitudes of epicenter. Precursor times are rarely given. In that case the writer reads the times from the published records. There are usually a number of peaks of noises prior to an earthquake. For evaluating the precursor time, the peak appearance having the highest power, which are usually closest to the earthquake occurrence, is assumed as the time of precursor.

\subsection{Data by the University of Electro-Communications}

The very first observation in Japan of electromagnetic emission related to earthquake occurrence was made by the University of Electro-Communications group (Gokhberg et al., 1982). Data No. 1 in Table 5 , that summarizes the results observed by the group, corresponds to that observation. The earthquake was a deep one beneath Kyoto Prefecture.

Nos. 2 and 3 are the data in relation to the medium-size earthquakes in Chiba and Ibaraki Prefectures, respectively (Yoshino et al., 1984). Nos. 4a, 4b and 4c are reported by Yoshino et al. (1985). No. 5-No. 29 are all taken from Yoshino et al. (1993).

\subsection{Data by the National Research Institute for Earth Science and Disaster Prevention}

Table 6 summarizes the data taken by National Research Institute for Earth Science and Disaster Prevention. The data in the early period of observation do not clearly mention the locations of epicenter, focal depths and precursor times as seen for Nos. 1-5 in Table 6 (Fujinawa et al., 1990). Data from No. 6 to No. 16 are all taken at NIE (Fujinawa and Takahashi, 1994).

Nos. 16, 17, 18, 19a, b and 20 are reported jointly by Natl. Res. Inst. Earth. Sci. Disast. Prev. and Commun. Res. Lab. (1992a, b, 1993, 1995), respectively.

\section{Relation between Earthquake Magnitude $(M)$ and Epicentral Distance $(D)$}

In order to see the nature of electromagnetic emission precursors cited in the last section, the writer first of all examines the relation between earthquake magnitude $(M)$ and epicentral distance $(D)$ in $\mathrm{km}$ in a manner similar to the analysis of earthquake precursors in Japan as made by Rikitake (1987a, b). Figure 2 shows the $M-\log D$ plots for the 20,34 and 21 electromagnetic emission data respectively obtained by the Oike, Yoshino and Fujinawa groups. Different marks are used in the figure for each group.

The most obvious feature is that the larger the magnitude, the longer the maximum distance of observable signal. It seems likely that the limit of observable distance is approximately given by a straight line shown in Fig. 2. The line is described by 


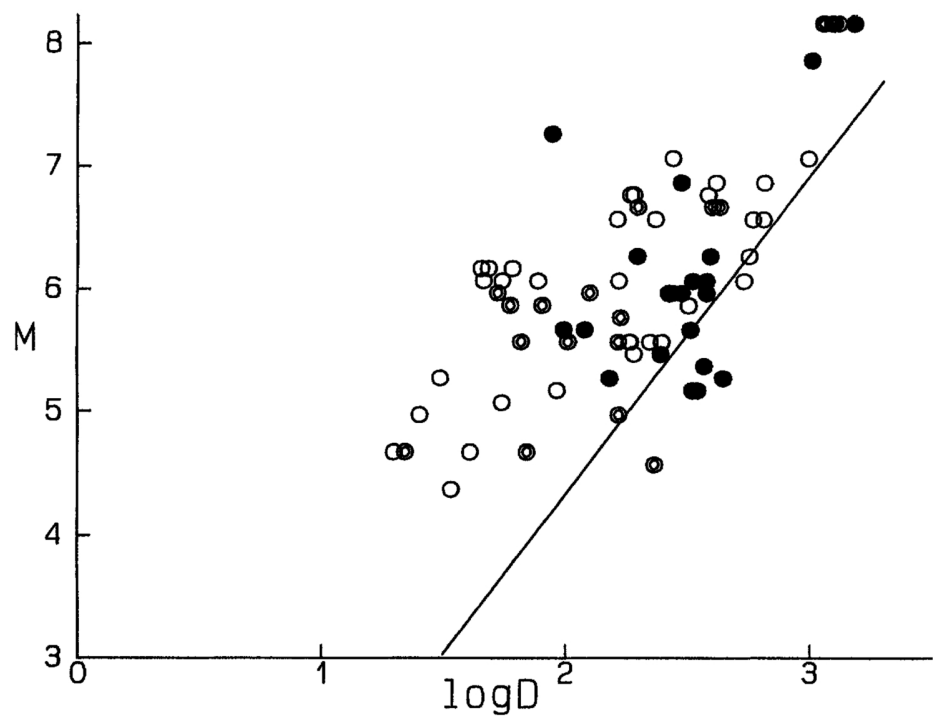

Fig. 2. The relation between main shock magnitude $(M)$ and epicentral distance of observation point ( $D$ in $\mathrm{km})$ for electromagnetic emission. The solid, open and double circles correspond to the data by Kyoto University, the University of ElectroCommunications and National Research Institute for Earth Science and Disaster Prevention, respectively.

$$
M=-0.87+2.6 \log D
$$

which has already been obtained for Japanese precursors in general as given in Rikitake (1987a). We thus conclude that the maximum detectable distance $\left(D_{\max }\right)$ of electromagnetic emission precursor is comparable to that of geophysical precursors in general.

The fact that the signal can be detected at an epicentral distance larger than $1000 \mathrm{~km}$ for an $M=8$ earthquake suggests that the signal is not propagated in the earth. The earth is conducting and dissipation of electromagnetic wave is considerable, but some precursory process excites an electromagnetic agitation in the air immediately above the epicentral area and that disturbance may possibly be propagated in the air reaching a considerably distant site.

It appears in Tables 4, 5 and 6 that there are relatively few instances for which the signals are observed simultaneously at a number of observation points. This is probably due to the fact that the data are not taken by an organized observation with multiple sensors. In the case of the 1994 Hokkaido Toho Oki earthquake $(M=8.1)$ when a well-organized observation net is operating, however, the signals are observed at many observation points.

In any case it is interesting that the $M-D_{\max }$ relation for electromagnetic emission precursor is approximately the same as that for other geophysical precursors.

\section{Relation between Earthquake Magnitude $(M)$ and Precursor Time (T)}

It has been customary to study the nature of earthquake precursor since the beginning of precursor analysis (Rikitake, 1975). The logarithm of the precursor time $(T)$ of some precursors such as geodetic deformation, change in geomagnetic field and the like is correlated to earthquake magnitude $(M)$ of main shock by

$$
\log T=a+b M
$$




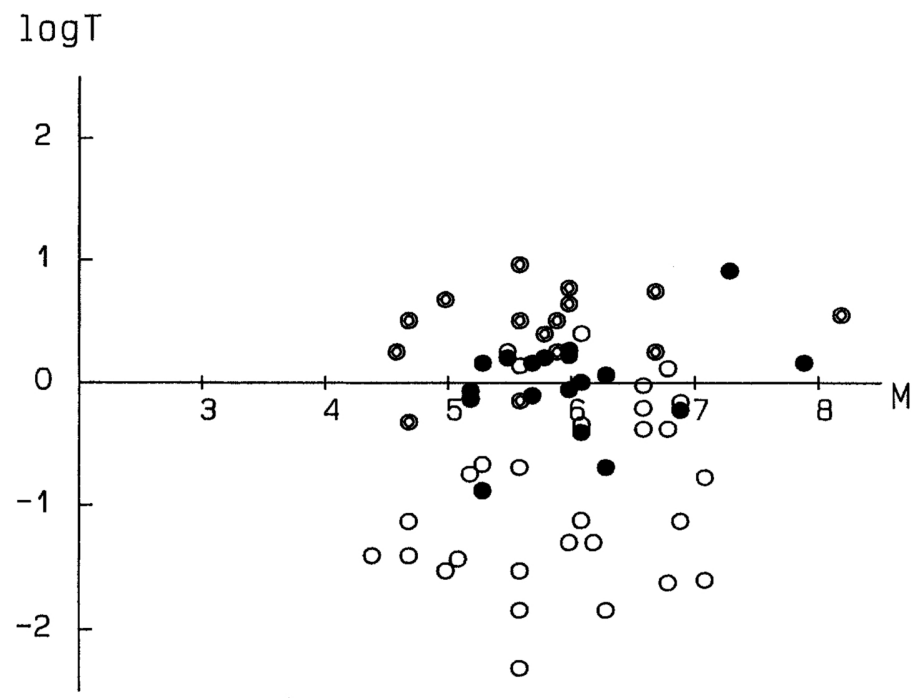

Fig. 3. The relation between $\operatorname{logarithmic}$ precursor time $(\log T: T$ in day) and main shock magnitude $(M)$. The symbols are the same as those in Fig. 3.

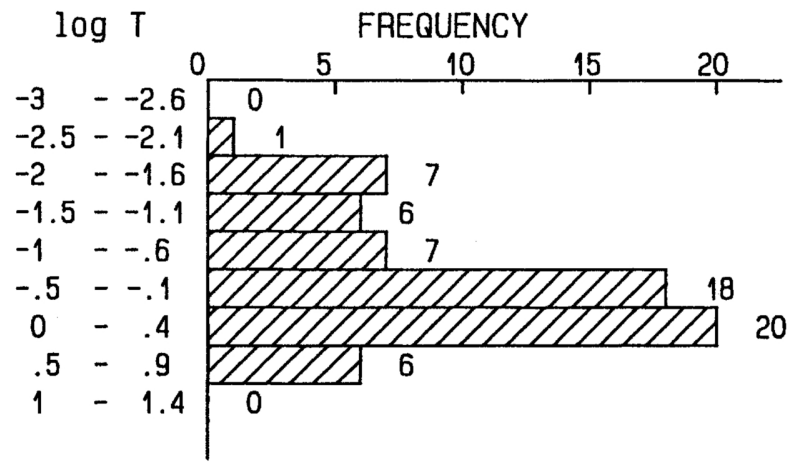

Fig. 4. Histogram for the distribution frequency of $\log T$ ( $T$ in day) for electromagnetic radiation precursors.

where $a$ and $b$ are constants, seems to have been established.

Meanwhile, there are precursors of another type for which $T$ does not depend on $M$ as is the case for foreshocks. $T$ is usually measured in days.

In the writer's former analysis (Rikitake, 1987a, b), only a few electromagnetic emission precursors were available, so that no reliable relation between $T$ and $M$ could be determined. With the larger data set in this paper, the $\log T-M$ plots may provide a fairly reliable relation between the two quantities (Fig. 3 ).

Looking at Fig. 3, we see no dependence of $\log T$ on $M$. A histogram that indicates the distribution frequency of $\log T$ is then drawn as can be seen in Fig. 4. The peak of precursor time appears around $\log T$ $=-0.5$ or $T=0.3$ day.

The distribution of $\log T$ can be approximately expressed by a Weibull distribution such as

$$
\lambda(s)=K s^{m}(s=\log T+c)
$$


Table 7. Probabilities for the main shock to occur within a time following an electromagnetic emission precursor.

\begin{tabular}{cc}
\hline Time $(t)$ & Probability \\
\hline 5 hour & 0.461 \\
12 hour & 0.631 \\
1 day & 0.751 \\
2 day & 0.847 \\
3 day & 0.891 \\
5 day & 0.932 \\
10 day & 0.968 \\
\hline
\end{tabular}

where $\lambda$ is the probability for $\log T$ to fall in an interval between $s$ and $s+\Delta s . c$ is a constant which may be chosen in such a way as to make actual calculation easy: a value of $c=3$ is assumed here.

Details of the distribution analysis are available elsewhere (Rikitake, 1987a) and will not be discussed here. Denoting a cumulative probability for $s$ to take on a value between 0 and $s$ by $P(s)$, we obtain

$$
P(s)=1-\exp \left[-K s^{m+1} /(m+1)\right]
$$

The parameters $K$ and $m$ are determined from the actual data as

$$
K /(m+1)=0.0436, m=3.15
$$

With these parameters, mean logarithmic precursor time and its standard deviation are estimated as

$$
\log T_{0}=-0.58\left(T_{0}=0.26 \text { day }\right) \text { and } \sigma=0.53 \text {. }
$$

We thus see that electromagnetic radiation precursor is essentially a short-term one.

Based on Eq. (4), the probabilities for the main shock to occur within a time $t$ following an electromagnetic emission precursor are estimated as shown in Table 7.

\section{Concluding Remarks}

Analyzing over 60 electromagnetic emission precursor data collected in Japan, it is revealed that there is some regularity between the magnitude $(M)$ of main shock, maximum detectable distance $\left(D_{\max }\right)$ and precursor time $(T)$ of data.

The relation between $M$ and $D_{\max }(\mathrm{km})$ as given in Eq. (1) is approximately the same as that for other geophysical precursors in general. It is remarkable that a precursor seems likely to be observed at a location some $1000 \mathrm{~km}$ distant from the epicenter for an earthquake of $M=8$ or so. Judging from strong dissipation of electromagnetic wave being propagated in the earth's crust, it is surmised that some source of electromagnetic emission seems to be produced over the epicentral area and the agitation is then propagated in the air reaching a very distant point.

No dependence of precursor time $(T)$ on magnitude can be seen in the present data. The situation is much the same as foreshock precursor. The mean precursor time of electromagnetic emission signal is estimated as 0.26 day. It is concluded that a precursor of this kind is essentially a short-term one.

The writer is thankful to Drs. H. Murakami and S. Park who kindly reviewed the manuscript and suggested possible improvements. 


\section{REFERENCES}

Faculty of Science, Kyoto University, Electromagnetic radiation phenomena recorded before and after the Hyogoken-Nanbu Earthquake, Rep. Coord. Comm. Earthq. Predict., 54, 713-720, 1995 (in Japanese).

Fraser-Smith, A. C., A. Bernardy, P. R. McGill, R. A. Helliwell, and O. G. Villard, Jr., Low-frequency magnetic field measurements near the epicenter of the $M_{s}=7.1$ Loma Prieta earthquake, Geophys. Res. Lett., 17, 1465-1468, 1990.

Fujinawa, Y. and K. Takahashi, Anomalous VLF subsurface electric field changes preceding earthquakes, Tech. Note Natl. Res. Inst. Earth Sci. Disast. Prev., 166, 61-75, 1994.

Fujinawa, Y., K. Takahashi, and T. Kumagai, ULF underground electric field variations as the imminent precursor of an earthquake, Zisin (J. Seismol. Soc. Japan), Ser. 2, 43, 287-290, 1990 (in Japanese).

Gokhberg, M. B., V. A. Norgounov, T. Yoshino, and I. Tomizawa, Experimental measurement of electromagnetic emissions possibly related to earthquakes in Japan, J. Geophys. Res., 87(B9), 7824-7827, 1982.

Natl. Res. Inst. Earth Sci. Disast. Prev. and Commun. Res. Lab., Anomalous underground electric field variations associated with the August 6, 1991 earthquake off Ibaraki, Rep. Coord. Comm. Earthq. Predict., 47, 107-117, 1992a (in Japanese).

Natl. Res. Inst. Earth Sci. Disast. Prev. and Commun. Res. Lab., Possible precursory subsurface electric field changes preceding the February 2, 1992 earthquake in the Tokyo bay, Rep. Coord. Comm. Earthq. Predict., 48, 195-199, 1992b (in Japanese).

Natl. Res. Inst. Earth Sci. Disast. Prev. and Commun. Res. Lab., On anomalous subsurface vertical electric field changes preceding the February 7, 1993 earthquake (M6.6, depth $30 \mathrm{~km}$ ) off the Noto Peninsula, north of central Japan, Rep. Coord. Comm. Earthq. Predict., 50, 496-500, 1993 (in Japanese).

Natl. Res. Inst. Earth Sci. Disast. Prev. and Commun. Res. Lab., Subsurface electric field changes related to the 1994 great Hokkaido-Toho-Oki earthquake, Rep. Coord. Comm. Earthq. Predict., 54, 38-41, 1995 (in Japanese).

Oike, K. and H. Murakami, On the relationship between shallow earthquakes and LF and VLF noises, Tech. Note Natl. Res. Inst. Earth Sci. Disast. Prev., 157, 221-271, 1993 (in Japanese).

Oike, K. and T. Ogawa, Electromagnetic radiations from shallow earthquakes observed in the LF range, J. Geomag. Geoelectr., 38, 1031-1040, 1986.

Oike, K. and T. Yamada, Observation system of electromagnetic radiations from earthquakes and some examples of records before and after the 1993 Hokkaido-Nansei-Oki earthquake, Tech. Note Natl. Res. Inst. Earth Sci. Disast. Prev., 166, 61-75, 1994 (in Japanese).

Rikitake, T., Earthquake precursors, Bull. Seismol. Soc. Am., 65, 1133-1162, 1975.

Rikitake, T., Earthquake precursors in Japan: precursor time and detectability, Tectonophysics, 136, 265-282, 1987a.

Rikitake, T., Magnetic and electric signals precursory to earthquakes: an analysis of Japanese data, J. Geomag. Geoelectr., 39, 47-61, $1987 \mathrm{~b}$.

Yoshino, T., I. Tomizawa, and S. Koyama, Observation of electromagnetic emission before and after an earthquake, Proc. Conductivity Anomaly Res., 137-143, 1984 (in Japanese).

Yoshino, T., I. Tomizawa, and T. Shibata, The possibility of using a direction finding technique to locate earthquake epicenters from electromagnetic precursor radiation, Ann. Geophys., 3(6), 727-730, 1985.

Yoshino, T., I. Tomizawa, and T. Sugimoto, Results of statistical analysis of low-frequency seismogenic EM emissions as precursors to earthquakes and volcanic eruptions, Phys. Earth Planet. Inter., 77, 21-31, 1993. 